\title{
Gas Phase Reactions of Trimethyl Borate with Phosphates and their Non-Covalent Complexes ${ }^{\dagger}$
}

\author{
Scott Gronert \\ Department of Chemistry and Biochemistry, San Francisco State University, San Francisco, California, USA
}

\author{
Richard A. J. O'Hair \\ School of Chemistry, University of Melbourne, Victoria, Australia
}

Using a quadrupole ion trap mass spectrometer, trimethyl borate was allowed to react with dihydrogen phosphate, deprotonated O-phosphoserine, and a set of hydrogen bonded complexes involving dihydrogen phosphate and neutral acids (phosphoric acid, acetic acid, serine, and O-phosphoserine). The reactions show a consistent pattern in which the initial attack leads to addition with the loss of one or two $\mathrm{CH}_{3} \mathrm{OH}$ molecules. Collision-activated dissociation (CAD) experiments on the reaction products generally lead to the loss of an additional $\mathrm{CH}_{3} \mathrm{OH}$ molecule. In no case is a partner from the original hydrogen-bonded complex lost. The results indicate that the reactions lead to structures where the phosphate and its complex partner are covalently bound to the boron. For each of the reactions, rate constants were determined. In the course of CAD experiments (up to $\mathrm{MS}^{5}$ ), several novel borophosphate structures were identified. The work is supported by ab initio calculations on selected species. (J Am Soc Mass Spectrom 2002, 13, 1088-1098) (c) 2002 American Society for Mass Spectrometry

$\mathrm{P}$ hosphates play a key role in biochemistry and the phosphorylation of a peptide is a common mechanism of activation. Phosphates offer opportunities for hydrogen bonding and non-covalent interactions of this type may provide clues to the site of phosphorylation in a peptide as well as the secondary structure of a protein. By their nature, the non-covalent interactions tend to be relatively weak and can be difficult to identify, especially by mass spectrometry. To explore these non-covalent interactions in greater detail, it would be useful to have a reagent that could efficiently convert them into covalent bonds that then could be probed by standard structural methods (i.e., collision-activated dissociation).

In this paper, we report the use of trimethyl borate (TMB) as reagent for cross-linking hydrogen-bonded complexes of inorganic and bioorganic phosphates. This compound and related boron reagents have previously been shown by Bowie and co-workers [1,2] to react readily with hydrogen-bonded alcohol/alkoxide complexes to give species where the boron is linked to both components of the original complex. TMB has also

Published online August 19, 2002

${ }^{t}$ Dedicated to Professor Charles H. DePuy on the occasion of his 75th birthday and in honor of his 2002 James Flack Norris Award in Physical Organic Chemistry.

Address reprint requests to Scott Gronert, Department of Chemistry and Biochemistry, San Francisco State University, San Francisco, California, 94132, USA. E-mail: sgronert@sfsu.edu and Richard O'Hair, School of Chemistry, University of Melbourne, Victoria 3031, Australia. E-mail: rohair@unimelb.edu.au been used as a reagent for identifying structural motifs in poly-functional molecules via positive ion mass spectrometry $[3,4]$. Despite the inherent low reactivity of phosphates in the gas phase [5], we have found that TMB gives rapid reactions that appear to involve the formation of covalent bonds between the partners in the phosphate complexes. As models for more complicated systems, we initially have investigated the reactions of TMB with complexes formed by combining $\mathrm{H}_{2} \mathrm{PO}_{4}^{-}$ with $\mathrm{H}_{3} \mathrm{PO}_{4}, \mathrm{CH}_{3} \mathrm{CO}_{2} \mathrm{H}$, serine, and O-phosphoserine. In addition, we have studied the reactions of TMB with the hydrogen-bonded dimer complex of O-phosphoserine.

\section{Experimental}

\section{Mass Spectrometry}

All experiments were completed at the University of Melbourne using a modified Finnigan LCQ (San Jose, CA) quadrupole ion trap mass spectrometer equipped with electrospray ionization (ESI) [6,7]. Precursors of the ionic species were dissolved in $\mathrm{CH}_{3} \mathrm{OH}$ or $\mathrm{CH}_{3} \mathrm{OH} /$ $\mathrm{H}_{2} \mathrm{O}$ mixtures $\left(10^{-4}-10^{-5} \mathrm{M}\right)$ and pumped through the electrospray interface at flow rates from 3-10 $\mu \mathrm{l} / \mathrm{min}$. Typical ESI conditions involved needle potentials from $3.5-4.5 \mathrm{kV}$ and heated capillary temperatures from $125-200{ }^{\circ} \mathrm{C}$. Once a steady signal was obtained, the trimethylborate (TMB) was introduced into the helium system via a custom gas-handling system. A related 
system has been described previously [7], but a brief overview is given here. The liquid TMB was delivered to a measured flow of helium $(1-21 / \mathrm{min})$ by a syringe pump. With TMB flows of $30-300 \mu \mathrm{l} / \mathrm{hr}$, rapid evaporation occurs at the syringe needle to give mixing ratios of $\sim 10^{2}-10^{4}$ (He/reagent). Most of the gas mixture is diverted to an exhaust system and $\sim 0.25 \mathrm{ml} / \mathrm{min}$ is carried through the LCQ's restriction capillary to the ion trap to establish a helium pressure of $1.75 \pm 0.2 \times$ $10^{-3}$ torr. At these pressures, the mean free path of the molecules is considerably longer than the dimensions of the trap and the loss of gases out of the end cap holes of the trap can be treated as an effusion process. The lighter helium atoms effusive more quickly than the reagent molecules and the mixing ratio must be corrected for differential effusion (square root of the mass ratio correction). Equation 1 describes the TMB pressure (torr) where $\mathrm{F}_{\mathrm{TMB}}$ is the reagent flow rate (liquid, $\mathrm{ml} / \mathrm{min}), \mathrm{d}_{\mathrm{TMB}}$ is the reagent density, $\mathrm{MW}_{\mathrm{TMB}}$ is the reagent molecular weight, $\mathrm{F}_{\mathrm{He}}$ is the helium flow rate (gas, moles/min), and $\mathrm{MW}_{\mathrm{He}}$ is the atomic weight of He. Typical TMB pressures were between $10^{-5}$ and $10^{-7}$ torr.

$$
\begin{aligned}
\mathrm{P}_{\mathrm{TMB}}= & 1.75 \times 10^{-3} \times \mathrm{F}_{\mathrm{TMB}} \times \mathrm{d}_{\mathrm{TMB}} / \mathrm{MW}_{\mathrm{TMB}} / \mathrm{F}_{\mathrm{He}} \\
& \times\left(\mathrm{MW}_{\mathrm{TMB}} / \mathrm{MW}_{\mathrm{He}}\right)^{1 / 2}
\end{aligned}
$$

Once an appropriate flow of the neutral reagent was established, the system was given several minutes for the reagent pressure to equilibrate to a steady state. Kinetic measurements were completed by varying the time delay between anion isolation and the expulsion of all ions to obtain a mass spectrum. In most cases, 13 different time delays were used in each run. Time delays and reagent flows were adjusted to obtain plots that covered 2-3 half-lives of the reactant ion. Reported rates are the average of at least 6 kinetic runs using at least three different reagent flow rates. Kinetic plots showed excellent linearity and generally gave correlation coefficients $\left(\mathrm{r}^{2}\right)$ greater than 0.98. In previous studies, it has been shown that this system gives rate constants comparable to those from a flowing afterglow instrument [7]. Other work from our laboratory indicates that the ion trap provides an environment that is effectively at ambient temperature ( $\sim 300 \mathrm{~K})[8]$.

\section{Computational}

Calculations were completed with the GAUSSIAN 94 [9] or GAUSSIAN 98 [10] quantum mechanical packages on an SGI Octane, an IBM $39 \mathrm{H}$, an HP 735, or a Pentium 3 computer. Geometries were initially optimized at the HF/6-31+G(d) level and frequency calculations were also completed at this level. All of the species in the study exhibited the proper number of imaginary frequencies. In addition, optimizations were completed at the MP2/6-31+G(d) level on the smaller species. Finally, single-point energies were calculated at
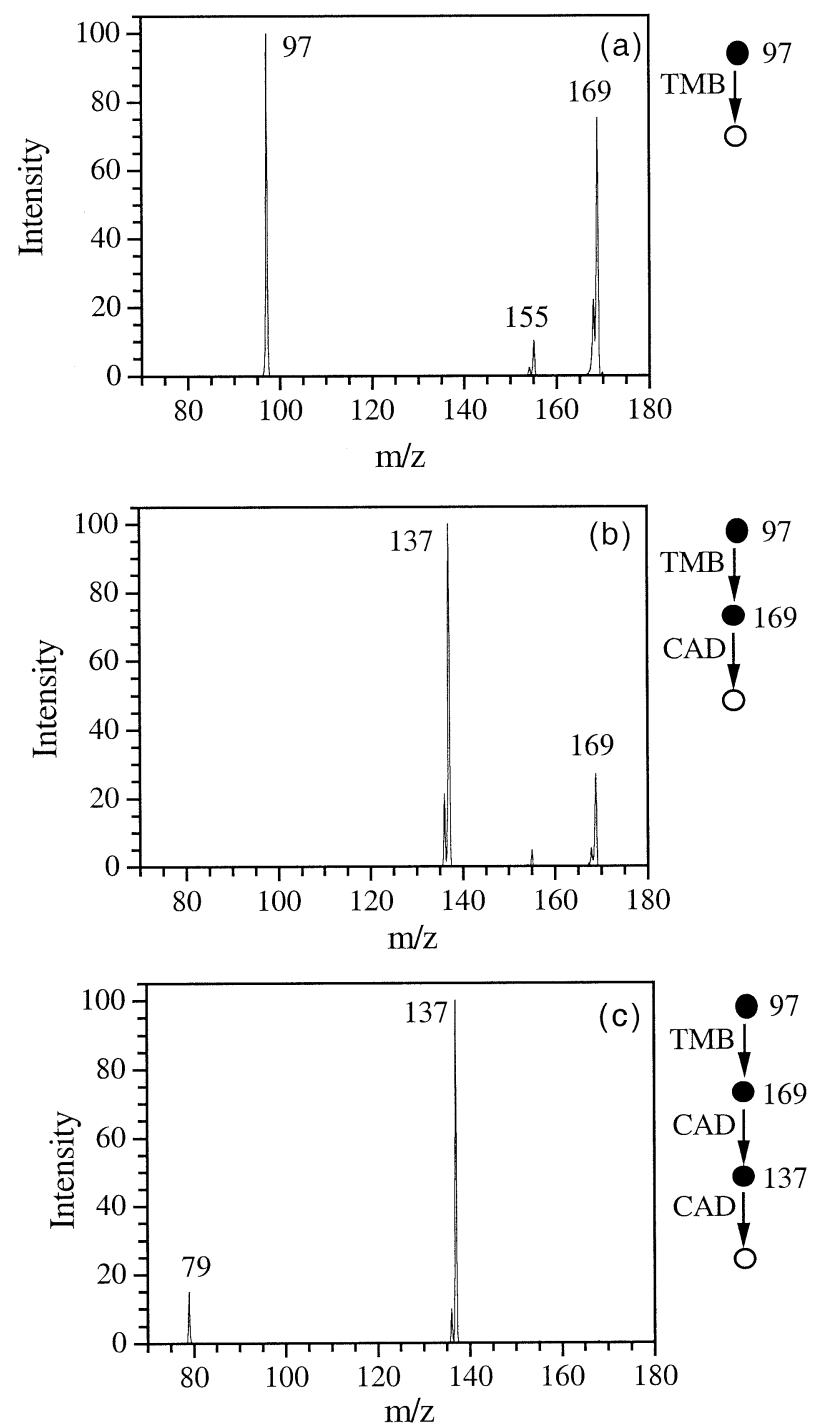

Figure 1. (a) Reaction of $\mathrm{H}_{2} \mathrm{PO}_{4}^{-}(m / z=97)$ with TMB. Addition with loss of $\mathrm{CH}_{3} \mathrm{OH}$ gives $\mathrm{m} / z=169$ (ion with ${ }^{10} \mathrm{~B}$ isotope is at 168). The minor ion at $m / z=155$ is the result of $\mathbf{I}$ reacting with traces on water in the trap. (b) CAD on $\mathrm{m} / \mathrm{z}=169$ causing a loss of $\mathrm{CH}_{3} \mathrm{OH}$. (c) $\mathrm{CAD}$ on $m / z=137$ to produce $\mathrm{PO}_{3}^{-}(\mathrm{m} / z=79)$.

the MP2 $/ 6-31+G(d, p)$ level on all the species (using the geometry from the highest level optimization). Energies reported in the text are at the MP2/6-31+G(d,p) level corrected for zero-point vibrational energies (ZPE, scaled by 0.9135$)$ [11].

\section{Results}

Reactions of $\mathrm{H}_{2} \mathrm{PO}_{4}^{-}$and $\mathrm{H}_{2} \mathrm{PO}_{4}^{-}\left(\mathrm{H}_{3} \mathrm{PO}_{4}\right)$ with Trimethyl Borate (TMB)

The mass spectrum from the reaction of $\mathrm{H}_{2} \mathrm{PO}_{4}^{-}$with TMB is shown in Figure 1a and data for all the reactions are compiled in Table 1 . The predominant feature of the spectrum is the formation of an ion at $m / z=169$ which corresponds to the addition of TMB with the loss of $\mathrm{CH}_{3} \mathrm{OH}$ via an addition/elimination mechanism 
Table 1. Major products from the reactions with trimethyl borate and their dominant CAD fragments ${ }^{\mathrm{a}}$

\begin{tabular}{|c|c|c|c|}
\hline Species & $\mathrm{MS}^{1}$ & $(\mathrm{M}-\mathrm{H})$ anion & Complex with $\mathrm{H}_{3} \mathrm{PO}_{4}$ \\
\hline $\mathrm{H}_{3} \mathrm{PO}_{4}$ & $\begin{array}{l}\mathrm{MS}^{2} \\
\mathrm{MS}^{3} \\
\mathrm{MS}^{4}\end{array}$ & $\begin{array}{l}+\mathrm{TMB}-\mathrm{CH}_{3} \mathrm{OH}(169) \\
-\mathrm{CH}_{3} \mathrm{OH}(137) \\
\mathrm{PO}_{3}^{-}(79)\end{array}$ & $\begin{array}{l}+\mathrm{TMB}-2 \mathrm{CH}_{3} \mathrm{OH}(235) \\
-\mathrm{CH}_{3} \mathrm{OH}(203) \\
\mathrm{HP}_{2} \mathrm{O}_{6}{ }^{-}(159)\end{array}$ \\
\hline $\mathrm{CH}_{3} \mathrm{CO}_{2} \mathrm{H}$ & $\begin{array}{l}\mathrm{MS}^{2} \\
\mathrm{MS}^{3} \\
\mathrm{MS}^{4}\end{array}$ & No $\operatorname{Rxn}$ & $\begin{array}{l}+\mathrm{TMB}-\mathrm{CH}_{3} \mathrm{OH}(229) \\
-\mathrm{CH}_{3} \mathrm{OH}(197) \\
-\mathrm{CH}_{3} \mathrm{CO}_{2} \mathrm{H}(137)\end{array}$ \\
\hline Serine & $\begin{array}{l}\mathrm{MS}^{2} \\
\mathrm{MS}^{3} \\
\mathrm{MS}^{4}\end{array}$ & $\begin{array}{l}+\mathrm{TMB}-\mathrm{CH}_{3} \mathrm{OH}(176) \\
-\mathrm{CH}_{3} \mathrm{OH}(144) \\
-\mathrm{CH}_{2}=\mathrm{O}(144)\end{array}$ & $\begin{array}{l}+\mathrm{TMB}-2 \mathrm{CH}_{3} \mathrm{OH}(242) \\
-\mathrm{CH}_{3} \mathrm{OH}(210) \\
-\mathrm{H}_{2} \mathrm{O}(192)\end{array}$ \\
\hline Serine ${ }^{* b}$ & $\begin{array}{l}\mathrm{MS}^{2} \\
\mathrm{MS}^{3} \\
\mathrm{MS}^{4} \\
\mathrm{MS}^{5} \\
\mathrm{MS}^{6} \\
\mathrm{MS}^{7}\end{array}$ & $\begin{array}{l}+\mathrm{TMB}-2 \mathrm{CH}_{3} \mathrm{OH}(224) \\
-\mathrm{CH}_{3} \mathrm{OH}(192) \\
\mathrm{PO}_{3}^{-}(79)\end{array}$ & $\begin{array}{l}+\mathrm{TMB}-2 \mathrm{CH}_{3} \mathrm{OH}(322) \\
-\mathrm{CH}_{3} \mathrm{OH}(290) \\
-\mathrm{H}_{2} \mathrm{O}(272) \\
-\mathrm{H}_{2} \mathrm{O}(254) \\
-\mathrm{CO}(226) \\
\mathrm{HP}_{2} \mathrm{O}_{6}^{-} \text {(159) }\end{array}$ \\
\hline
\end{tabular}

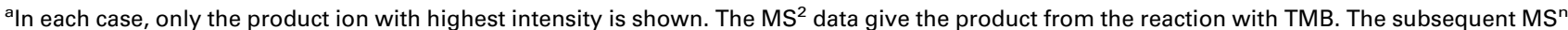
levels represent sequential CAD of the dominant ion from the previous level. In parentheses, the $\mathrm{m} / \mathrm{z}$ values of the ions are shown.

berine* represents O-phosphoserine.

(Scheme 1). It should be noted that in all the phosphate reaction schemes, we assume that the boron adds to the anionic site. Although we have shown that this is not true for the reactions of deprotonated amino acids [12], computational work on the reaction of $\mathrm{H}_{2} \mathrm{PO}_{4}^{-}$with TMB indicates that addition does occur at the oxyanion site. There are two reasonable structures for the ion $m / z=169$. The boron could be tetravalent as part of a four-membered ring (Ia) or trivalent with an anionic phosphate ligand (Ib).<smiles>CO[PH]1(OC)OP(=O)(O)O1</smiles><smiles>COB(OC)OP(=O)([O-])O</smiles>

$A b$ initio calculations at the $\mathrm{MP} 2 / 6-31+\mathrm{G}(\mathrm{d}, \mathrm{p}) / /$ $\mathrm{MP} 2 / 6-31+\mathrm{G}(\mathrm{d})$ indicate that the closed form of the anion, Ia, is about $3.5 \mathrm{kcal} / \mathrm{mol}$ more stable than the open structure (Table 2, Figure 2). This suggests the advantage of the extra bond to boron barely overcomes the strain of the four-membered ring. The calculated barrier between the two species is small $(4.1 \mathrm{kcal} / \mathrm{mol}$

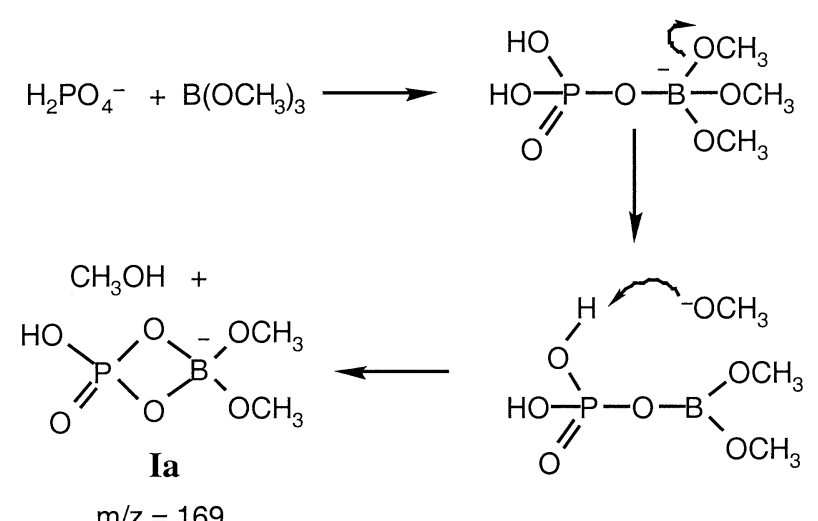

Scheme 1 relative to Ia) and therefore they are probably in a dynamic equilibrium (of course, entropy corrections should favor the open form). This type of equilibrium appears to be common for these boron species (see below) and in the schemes we will show only one form of the ion (open or closed) although both could play a role in the chemistry (closed forms will be consistently labeled as ' $a$ ' and open forms as ' $b$ ' throughout the text). Other ions in the spectrum at higher mass (not shown) correspond to secondary reactions of I with TMB in the ion trap (an ion is also seen at $m / z=155$ that is related to I, but has exchanged a methoxy for a hydroxy group. It is most likely arises from a reaction of $\mathbf{I}$ with traces of water in the ion trap).

When subjected to collision-activated dissociation (CAD) conditions in the ion trap, the product ion $(\mathrm{m} / \mathrm{z}=$ 169) loses a second $\mathrm{CH}_{3} \mathrm{OH}$ to produce an ion at $m / z=$ 137 (II) that has a tricoordinate boron (Figure 1b). When subjected to CAD, II exclusively produces $\mathrm{PO}_{3}^{-}$(Figure 1c, eq 2).

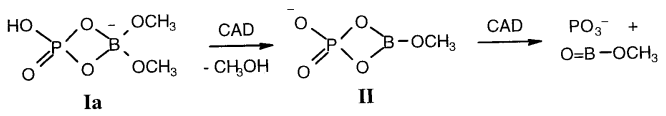

The reaction of the $\mathrm{H}_{2} \mathrm{PO}_{4}^{-}\left(\mathrm{H}_{3} \mathrm{PO}_{4}\right)$ complex with TMB produces a somewhat different pattern (Figure $3 a)$. First, the reaction leads to the immediate loss of two $\mathrm{CH}_{3} \mathrm{OH}$ molecules to produce an ion at $m / z=235$. This represents an interesting example where a non-covalent complex appears to exhibit broader reactivity than the analogous, monomeric ion. Clearly, the presence of additional nucleophilic sites in the complex allows for the facile loss of the second methanol despite the fact the initial addition to the TMB is probably less exothermic than with $\mathrm{H}_{2} \mathrm{PO}_{4}^{-}$. When subjected to $\mathrm{CAD}$, the ion at $m / z=235$ predominately loses $\mathrm{CH}_{3} \mathrm{OH}$ as well as 
Table 2. Computational data for the reactions of $\mathrm{TMB}^{\mathrm{a}}$

\begin{tabular}{|c|c|c|c|c|}
\hline Species & MP2 & ZPE & Reaction Process & $\begin{array}{l}\text { Reacion } \\
\text { Energy }\end{array}$ \\
\hline la & -896.32985 & 0.12771 & $\mathbf{l a} \Rightarrow \mathbf{l b}$ & 3.5 \\
\hline lb & -896.32451 & 0.12788 & & \\
\hline II & -780.89530 & 0.07022 & & \\
\hline Illa ${ }^{b}$ & -1423.86749 & 0.12672 & IIla $\Rightarrow$ IIIb & -0.7 \\
\hline$I I I l^{b}$ & -1423.86889 & 0.12698 & & \\
\hline$I \mathrm{Ia}^{\mathrm{b}}$ & -1308.42332 & 0.06827 & $\mathrm{IVa} \Rightarrow \mathrm{IVb}$ & 16.8 \\
\hline $\mathrm{IVb}^{\mathbf{b}}$ & -1308.39569 & 0.06741 & & \\
\hline \multirow[t]{2}{*}{ V } & -1124.84904 & 0.19677 & $\mathbf{V} \Rightarrow \mathbf{V l a}+\mathrm{CH}_{3} \mathrm{OH}$ & 25.7 \\
\hline & & & $\mathbf{V} \Rightarrow \mathbf{l a}+\mathrm{CH}_{3} \mathrm{C}(\mathrm{O}) \mathrm{OH}$ & 29.6 \\
\hline \multirow[t]{3}{*}{ Vla } & -1009.41174 & 0.13844 & $\mathrm{Vla} \Rightarrow \mathrm{Vlb}$ & 7.7 \\
\hline & & & $\mathrm{Vla} \Rightarrow \mathrm{VII}+\mathrm{CH}_{3} \mathrm{OH}$ & 32.1 \\
\hline & & & Vla $\Rightarrow$ II $+\mathrm{CH}_{3} \mathrm{C}(\mathrm{O}) \mathrm{OH}$ & 28.3 \\
\hline Vlb & -1009.39915 & 0.13812 & & \\
\hline VII & -893.96470 & 0.08053 & & \\
\hline$\left(\mathrm{CH}_{3} \mathrm{O}\right)_{3} \mathrm{~B}-\mathrm{OCH}_{3}^{-}$ & -484.19184 & 0.18557 & loss of TMB & -52.1 \\
\hline$\left(\mathrm{CH}_{3} \mathrm{O}\right)_{3} \mathrm{~B}-\mathrm{OC}(\mathrm{O}) \mathrm{CH}_{3}$ & -597.28222 & 0.19675 & loss of TMB & -23.1 \\
\hline$\left(\mathrm{CH}_{3} \mathrm{O}\right)_{3} \mathrm{~B}$ & -369.33711 & 0.14327 & & \\
\hline $\mathrm{CH}_{3} \mathrm{C}(\mathrm{O}) \mathrm{OH}$ & -228.46988 & 0.06666 & deprotonation & 344.9 \\
\hline $\mathrm{CH}_{3} \mathrm{OH}$ & -115.39343 & 0.05519 & deprotonation & 382.7 \\
\hline $\mathrm{CH}_{3} \mathrm{C}(\mathrm{O}) \mathrm{O}^{-}$ & -227.90686 & 0.05193 & & \\
\hline $\mathrm{CH}_{3} \mathrm{O}^{-}$ & -114.76988 & 0.04027 & & \\
\hline
\end{tabular}

${ }^{a}$ Absolute energies in Hartree. Reaction energies in kcal/mol. MP2/6-31+G(d,p)//MP2/6-31+G(d) level unless noted otherwise. Reaction energies corrected for Hartree-Fock ZPE (scaled by 0.9135 ).

bMP2/6-31+G(d,p)//HF/6-31+G(d) level.

$\mathrm{H}_{2} \mathrm{O}$ to a lesser extent (Figure 3b). The loss of $\mathrm{CH}_{3} \mathrm{OH}$ rather than $\mathrm{H}_{3} \mathrm{PO}_{4}$ is compelling evidence that the boron is covalently bound to both phosphates. Structures of possible reaction products are outlined in Scheme 2. We have completed calculations at the MP2/ $6-31+\mathrm{G}(\mathrm{d}, \mathrm{p}) / / \mathrm{HF} / 6-31+\mathrm{G}(\mathrm{d})$ level on the $m / z=235$ ion. The form with the trivalent boron, IIIb (Table 2), is calculated as being only $1 \mathrm{kcal} / \mathrm{mol}$ more stable than the closed form analogous to Ia with a tetravalent boron (IIIa, not shown). This again points out the flexibility of the boron valency and suggests that tri- and tetravalent boron species can co-exist on the potential energy surfaces. Another alternative structure for the $m / z=235$ ion would be a hydrogen-bonded complex of II with $\mathrm{H}_{3} \mathrm{PO}_{4}$, but this should have a high probability of losing phosphoric acid during CAD and therefore is not consistent with the data. For example, the $\mathrm{H}_{2} \mathrm{PO}_{4}^{-}$ $\left(\mathrm{H}_{3} \mathrm{PO}_{4}\right)$ complex splits to give $\mathrm{H}_{2} \mathrm{PO}_{4}^{-}$under $\mathrm{CAD}$ conditions.

The proposed spirocyclic structure of the $\mathrm{m} / \mathrm{z}=203$ ion (Scheme 2) may appear unusual or highly strained; however, there is condensed phase data for salts with this same structural motif [13]. Other bicyclic structures (e.g., with $\mathrm{P}-(\mathrm{O})_{2}-\mathrm{P}-(\mathrm{O})_{2}-\mathrm{B}$ rather than a $\mathrm{P}-(\mathrm{O})_{2}-\mathrm{B}-(\mathrm{O})_{2}-\mathrm{P}$ bridging framework) would require cleavages of $\mathrm{P}-\mathrm{O}$ bonds during the losses of $\mathrm{CH}_{3} \mathrm{OH}$ and seem less likely. We also considered a monocyclic form of the ion (IVb, not shown), but calculations at the MP2/6$31+\mathrm{G}(\mathrm{d}, \mathrm{p}) / / \mathrm{HF} / 6-31+\mathrm{G}(\mathrm{d})$ level favor the spirocyclic form by nearly $17 \mathrm{kcal} / \mathrm{mol}$. The loss of $\mathrm{HOBO}$ from the spirocyclic structure (Figure 3c) requires considerable reorganization of the heavy atom framework, but given the variety of the coordination states of boron (tri- or tetracoordinate) and phosphorous (tri-, tetra-, or pentacoordinate), it is reasonable to assume that a low energy pathway is available and that the driving force is the formation of stable products. The $\mathrm{m} / \mathrm{z}=159$ is an unusual phosphorous poly-oxide and there appears to be only one report of a related species in condensed phase work [14]. It is essentially the condensation product of metaphosphate with its conjugate acid and it should be highly susceptible to hydrolysis in solution; however, in the gas phase, like $\mathrm{PO}_{3}^{-}$, it should be relatively stable [15].

\section{Reactions of $\mathrm{H}_{2} \mathrm{PO}_{4}^{-}\left(\mathrm{CH}_{3} \mathrm{CO}_{2} \mathrm{H}\right)$ with $\mathrm{TMB}$}

Although the $\mathrm{M}-\mathrm{H}$ anion of acetic acid is effectively unreactive with $\mathrm{TMB}$, the complex of $\mathrm{H}_{2} \mathrm{PO}_{4}^{-}$and acetic acid reacts to give a product at $m / z=229(\mathbf{V})$ that corresponds to addition with the loss of $\mathrm{CH}_{3} \mathrm{OH}$ (Figure $4 \mathrm{a})$. When subjected to CAD (Figure $4 \mathrm{~b}$ ), this product ion losses a second $\mathrm{CH}_{3} \mathrm{OH}$ to give an ion at $\mathrm{m} / \mathrm{z}=197$ (VI). The loss of $\mathrm{CH}_{3} \mathrm{OH}$ during the initial reaction followed by the second $\mathrm{CH}_{3} \mathrm{OH}$ loss during CAD once again provides strong evidence that both the acetate and phosphate are bound to the boron. If the initial product were simply a cluster of I complexed to $\mathrm{CH}_{3} \mathrm{CO}_{2} \mathrm{H}$, one would expect that loss of $\mathrm{CH}_{3} \mathrm{CO}_{2} \mathrm{H}$ would be an important $\mathrm{CAD}$ channel, but it is not. For example, $\mathrm{CAD}$ of the reactant ion, $\mathrm{H}_{2} \mathrm{PO}_{4}^{-}\left(\mathrm{CH}_{3} \mathrm{CO}_{2} \mathrm{H}\right)$, cleanly leads to $\mathrm{H}_{2} \mathrm{PO}_{4}^{-}$by loss of $\mathrm{CH}_{3} \mathrm{CO}_{2} \mathrm{H}$. When VI is subjected to $\mathrm{CAD}$ (Figure $4 \mathrm{c}$ ), $\mathrm{CH}_{3} \mathrm{CO}_{2} \mathrm{H}$ is lost to give an ion at $\mathrm{m} / \mathrm{z}=137$ that appears to be equivalent to II 


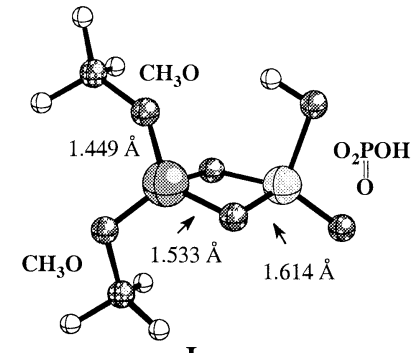

Ia
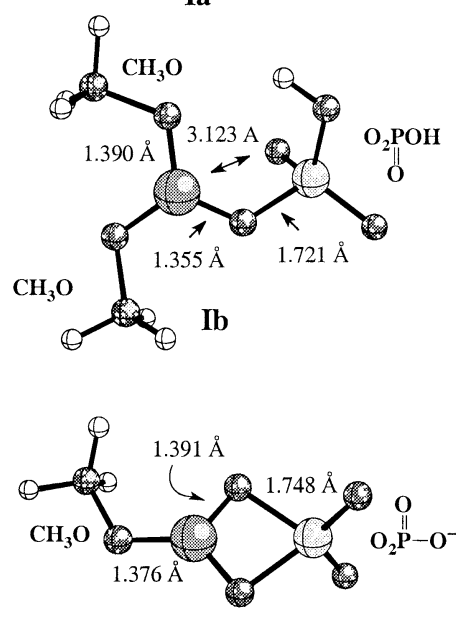

II
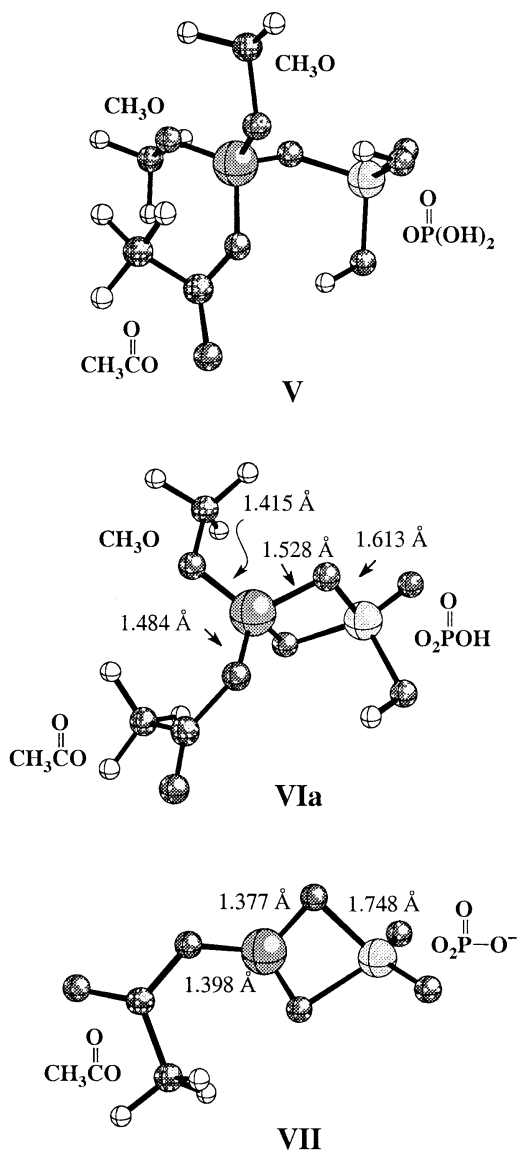

Figure 2. Computed structures (MP2/6-31+G(d)) for species formed in reactions with TMB. The ligands on the central boron are labeled in the drawings.
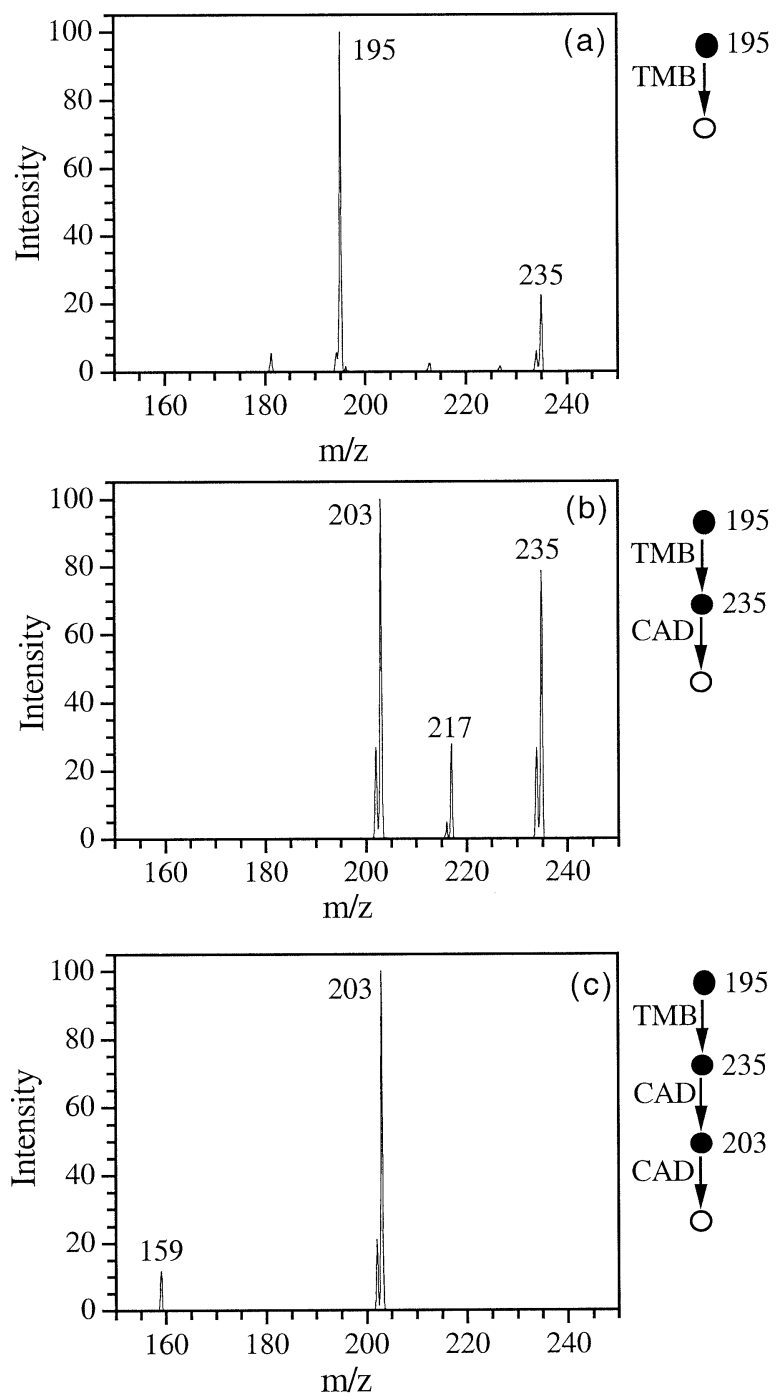

Figure 3. (a) Reaction of $\mathrm{H}_{2} \mathrm{PO}_{4}^{-}\left(\mathrm{H}_{3} \mathrm{PO}_{4}\right)$ complex $(\mathrm{m} / \mathrm{z}=195)$ with TMB to give addition with the loss of $2 \mathrm{CH}_{3} \mathrm{OH}$ molecules $(\mathrm{m} / \mathrm{z}=235)$. (b) CAD of $m / z=235$ giving a loss of $\mathrm{H}_{2} \mathrm{O}(\mathrm{m} / \mathrm{z}=217)$ and loss of $\mathrm{CH}_{3} \mathrm{OH}(\mathrm{m} / \mathrm{z}=203)$. (c) CAD of $\mathrm{m} / \mathrm{z}=203$ to produce $\mathrm{HP}_{2} \mathrm{O}_{6}^{-}(m / z=159)$.

(see above). Structures on this reaction path are shown in Scheme 3. Calculations (Table 2) indicate that the closed form, VIa, is preferred by nearly $8 \mathrm{kcal} / \mathrm{mol}$ over the open form (VIb, not shown).

A curious aspect of the reaction pathway is that there is a distinct preference in each step with regards to the ligand that is lost from boron, but it is not always the same ligand that is preferentially lost. During the addition and the first $\mathrm{CAD}$ process, $\mathrm{CH}_{3} \mathrm{OH}$ is lost almost exclusively, but in the final $\mathrm{CAD}, \mathrm{CH}_{3} \mathrm{CO}_{2} \mathrm{H}$ is lost. Clearly, the propensity for losing a ligand from these boron species is not governed by the basicity of the anionic leaving group (otherwise $\mathrm{H}_{3} \mathrm{PO}_{4}$ should be a common loss because $\mathrm{H}_{2} \mathrm{PO}_{4}^{-}$is the weakest base among the ligands) and must be controlled by the overall thermodynamics of the process. To explore this issue, we have computationally modeled the species 


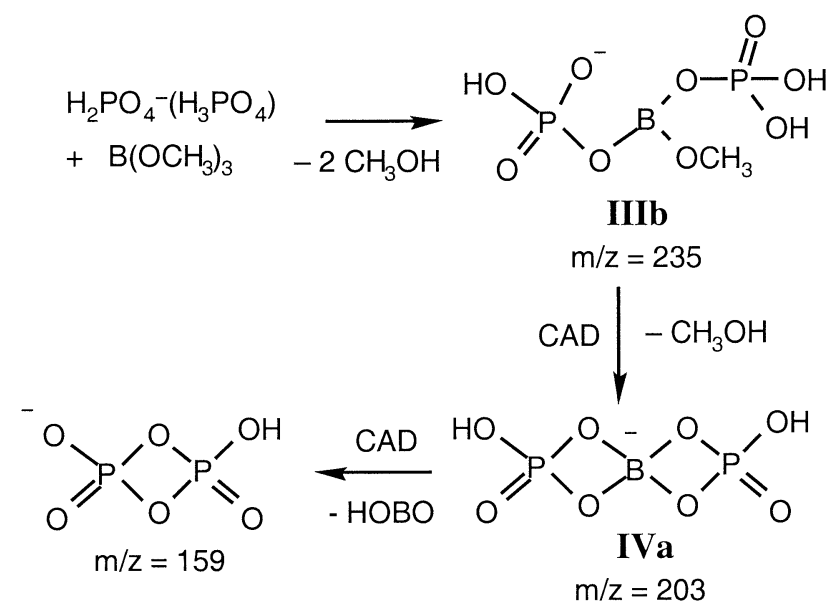

Scheme 2

involved in the reaction and CAD processes. There is considerable conformational freedom in these molecules and we have explored multiple conformations at low levels of theory (PM3)[16] and used the best for the $\mathrm{ab}$ initio analysis (MP2/6-31+G(d,p)//MP2/6$31+G(d))$. This does not guarantee that the lowest energy conformation was found in each case, but should be satisfactory for a qualitative analysis of the potential energy surface. The results are listed in Table 2 and representations of the structures are shown in Figure 2. As a starting point, we begin with the initial reaction product, $\mathbf{V}$. During $\mathrm{CAD}$, it could lose either $\mathrm{CH}_{3} \mathrm{OH}$ to give VIa or $\mathrm{CH}_{3} \mathrm{CO}_{2} \mathrm{H}$ to give Ia. In both cases, the phosphate becomes a bidentate ligand in the product ion and boron remains tetracoordinate. The calculations indicate that the former process is favored thermodynamically by $4 \mathrm{kcal} / \mathrm{mol}$. The thermodynamic preference for losing methanol rather than one of the other ligands can be rationalized in a straightforward manner. In the dissociation process, the departing ligand exchanges a bond to boron for a bond to a proton; therefore, it is the relative difference in proton (PA) vs. borate affinity that determines the thermochemistry. Because the proton affinity scale spans a much wider range than any other affinity scale, it should dominate and the ligand with the highest proton affinity should be preferentially lost. For example, the calculated difference in TMB affinity of $\mathrm{CH}_{3} \mathrm{O}^{-}$and $\mathrm{CH}_{3} \mathrm{CO}_{2}^{-}$is only $29 \mathrm{kcal} / \mathrm{mol}$ whereas the difference in proton affinities of these ligands is $38 \mathrm{kcal} / \mathrm{mol}$ at the same level of theory. Given this analysis, it is easy to see why $\mathrm{CH}_{3} \mathrm{OH}$ is generally lost in the TMB reaction products $\left(\mathrm{CH}_{3} \mathrm{O}^{-}\right.$ has the highest proton affinity of all the ligands in the study). From VIa, either $\mathrm{CH}_{3} \mathrm{OH}$ or $\mathrm{CH}_{3} \mathrm{CO}_{2} \mathrm{H}$ could be lost to give VII or II, respectively, but now, the calculations indicate a significant preference for $\mathrm{CH}_{3} \mathrm{CO}_{2} \mathrm{H}$ loss. The key difference is that in the first two ligand expulsions (i.e., the $\mathrm{CH}_{3} \mathrm{OH}$ in the reaction and the $\mathrm{CH}_{3} \mathrm{OH}$ in the first $\mathrm{CAD}$ ), the boron remains tetracoordinate, but in the last loss, it is forced to be tricoordi-
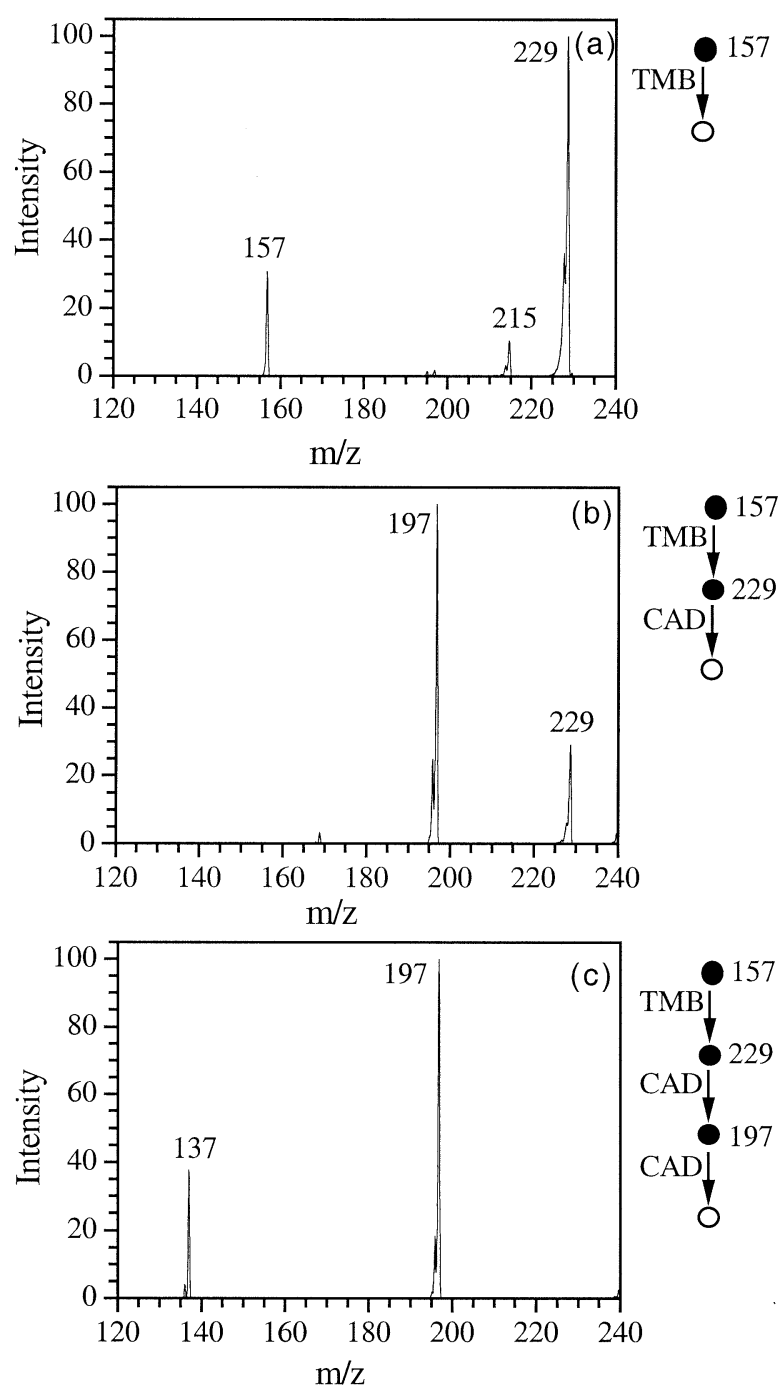

Figure 4. (a) Reaction of the $\mathrm{H}_{2} \mathrm{PO}_{4}^{-}\left(\mathrm{CH}_{3} \mathrm{CO}_{2} \mathrm{H}\right)$ complex $(\mathrm{m} / \mathrm{z}=$ 157) with TMB to give addition with loss of $\mathrm{CH}_{3} \mathrm{OH}$ at $\mathrm{m} / \mathrm{z}=229$. (b) $\mathrm{CAD}$ of $m / z=229$ causing loss of $\mathrm{CH}_{3} \mathrm{OH}(\mathrm{m} / z=197)$. (c) $\mathrm{CAD}$ of $m / z=197$ causing loss of $\mathrm{CH}_{3} \mathrm{CO}_{2} \mathrm{H}(\mathrm{m} / \mathrm{z}=137)$.

nate. As a result, the boron has a free p-orbital to $\pi$-bond with the ligands (shortening of the B-O bonds in the tricoordinate boron species (Figure 2) supports this analysis). It is well known that $\mathrm{CH}_{3} \mathrm{O}$ is a better $\pi$-donor than $\mathrm{CH}_{3} \mathrm{CO}_{2}$ and therefore can better stabilize the tricoordinate boron species. Consequently, the $\mathrm{CH}_{3} \mathrm{O}$ group is preferentially retained when a tricoordinate boron species is formed. Although the preferred fragmentations are consistent with the thermodynamics of the processes, it is possible that they are rooted in purely kinetic factors unrelated to the thermodynamics (given the complexity of the surface, we did not computationally search for the expulsion transition statesnumerous possibilities exist involving open and closed forms of the ions and the option of a 6-centered transition state for acetic acid loss as well as multiple conformations for each case would need to be considered). 


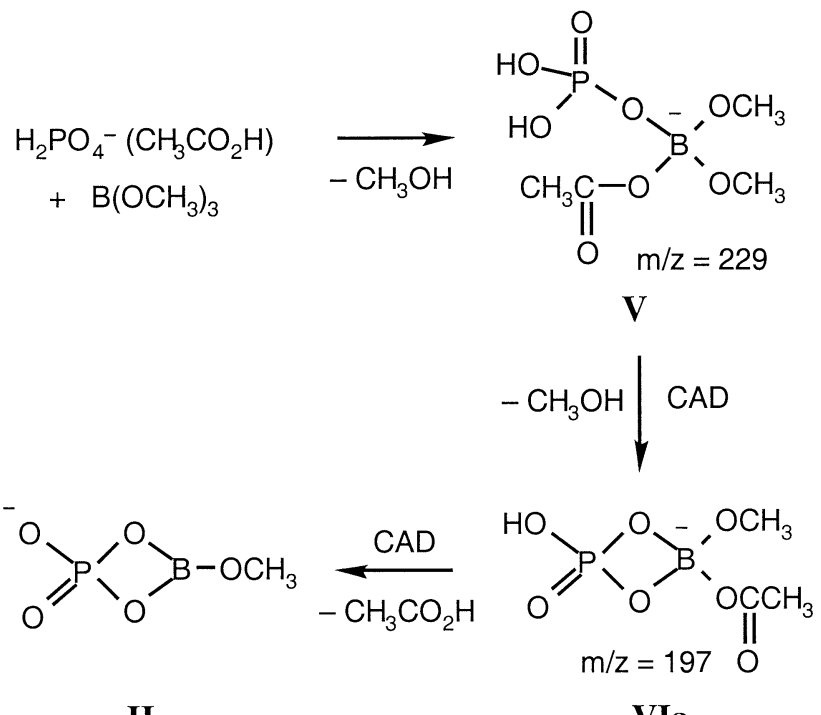

Scheme 3

Reactions of Deprotonated Phosphoserine and its Complexes with TMB

With phosphoserine, it is unclear whether the $\mathrm{M}-\mathrm{H}$ anion is a carboxylate or phosphate anion because both sites should have fairly similar gas phase proton affinities. For example there is not a large difference in the gas phase acidities of phosphoric acid [17] and serine [18]. When the $\mathrm{M}-\mathrm{H}$ anion from phosphoserine is allowed to react with $\mathrm{TMB}$, products at $\mathrm{m} / \mathrm{z}=256$ and $\mathrm{m} / \mathrm{z}=224$ dominate, and correspond to addition followed by the loss of one or two $\mathrm{CH}_{3} \mathrm{OH}$ molecules (Figure 5a). When the ion at $m / z=224$ is subjected to CAD (Figure $5 b$ ), several products are formed corresponding to the loss of $\mathrm{H}_{2} \mathrm{O}(\mathrm{m} / \mathrm{z}=206)$, the loss of $\mathrm{CH}_{3} \mathrm{OH}(\mathrm{m} / \mathrm{z}=192)$, the loss of $\mathrm{C}_{4} \mathrm{H}_{6} \mathrm{NO}_{3}$ to give $\mathrm{H}_{2} \mathrm{PO}_{4}^{-}$, and the loss of $\mathrm{C}_{4} \mathrm{H}_{8} \mathrm{NO}_{4}$ to give $\mathrm{PO}_{3}^{-}$. Secondary ions are seen at $m / z=169\left(\mathrm{H}_{2} \mathrm{PO}_{4}^{-}+\mathrm{TMB}-\right.$ $\left.\mathrm{CH}_{3} \mathrm{OH}\right), 241\left(\mathrm{H}_{2} \mathrm{PO}_{4}^{-}+2 \mathrm{TMB}-2 \mathrm{CH}_{3} \mathrm{OH}\right)$, and 264 $\left(m / z=224+\mathrm{TMB}-2 \mathrm{CH}_{3} \mathrm{OH}\right)$. When subjected to $\mathrm{CAD}$, the ion at $m / z=192$ yields $\mathrm{PO}_{3}^{-}$. A possible reaction pathway is given in Scheme 4 . We suggest that the initial reaction leads to the formation of a bicyclic structure involving the amino acid and the phosphate side chain. The amino acid binding is consistent with extensive studies that we have completed on the gas phase reactions of simple amino acids with boron and aluminum reagents [12]. There are other possible bonding schemes (e.g., the phosphate acts as a bidentate ligand and the amine does not coordinate with boron-analogous to species like VIa), but semi-empirical calculations (AM1 and PM3)[16] suggest that the arrangement shown in Scheme 4 is preferred. Loss of the third $\mathrm{CH}_{3} \mathrm{OH}$ group to give an ion at $m / z=192$ requires the formation of a tricoordinate boron species, VIII. During $\mathrm{CAD}, \mathrm{PO}_{3}^{-}$is expelled and the likely product is a novel boron hetero-
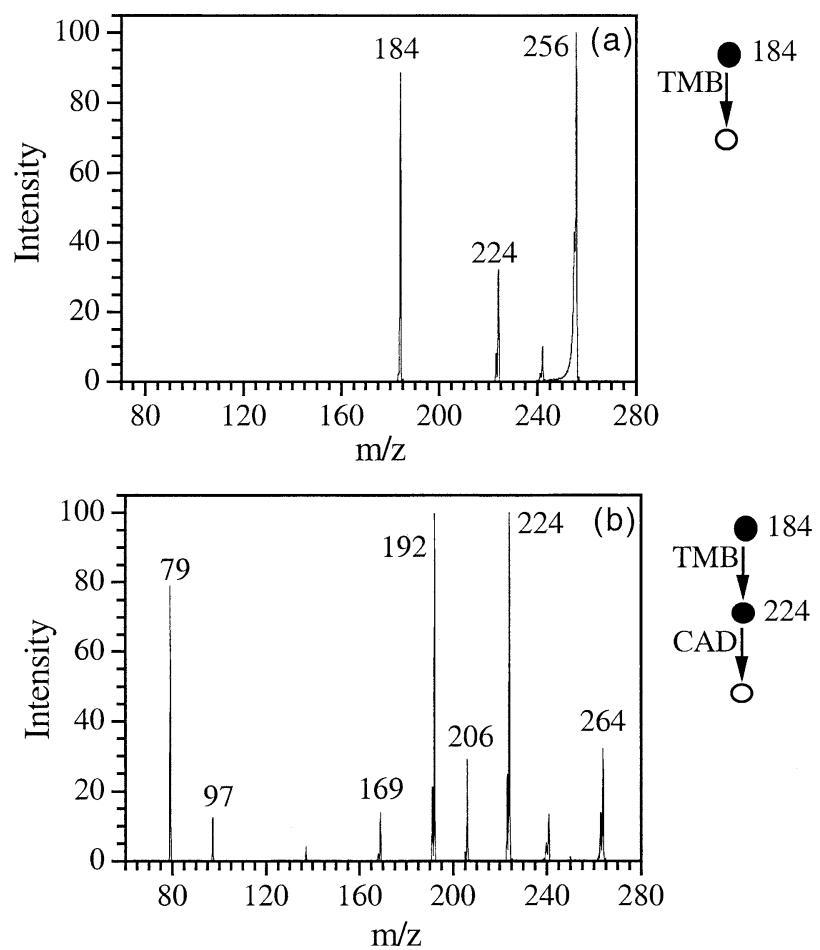

Figure 5. (a) Reaction of phosphoserine $(\mathrm{M}-\mathrm{H})$ anion $(\mathrm{m} / \mathrm{z}=$ 184) with TMB to give addition with loss of one or two $\mathrm{CH}_{3} \mathrm{OH}$ molecules $(\mathrm{m} / \mathrm{z}=256$ and 224, respectively). (b) CAD of $\mathrm{m} / \mathrm{z}=224$ to give multiple products including loss of $\mathrm{H}_{2} \mathrm{O}(\mathrm{m} / \mathrm{z}=206)$, loss of $\mathrm{CH}_{3} \mathrm{OH}(\mathrm{m} / \mathrm{z}=192), \mathrm{H}_{2} \mathrm{PO}_{4}^{-}(\mathrm{m} / \mathrm{z}=97)$, and $\mathrm{PO}_{3}^{-}(\mathrm{m} / \mathrm{z}=79)$. Secondary reaction products are seen at $m / z=169,241$, and 264 .

cycle, IX. In related work on the reactions of serine anions with $\mathrm{BH}_{3}$, we have found evidence for the formation of bicyclic species related to IX. Although the bicyclic structure must have some strain, computational work indicates that IX is much more stable than logical monocyclic alternatives (i.e., species with a $\mathrm{B}=\mathrm{N}$ bond and one of the oxygen ligands protonated).

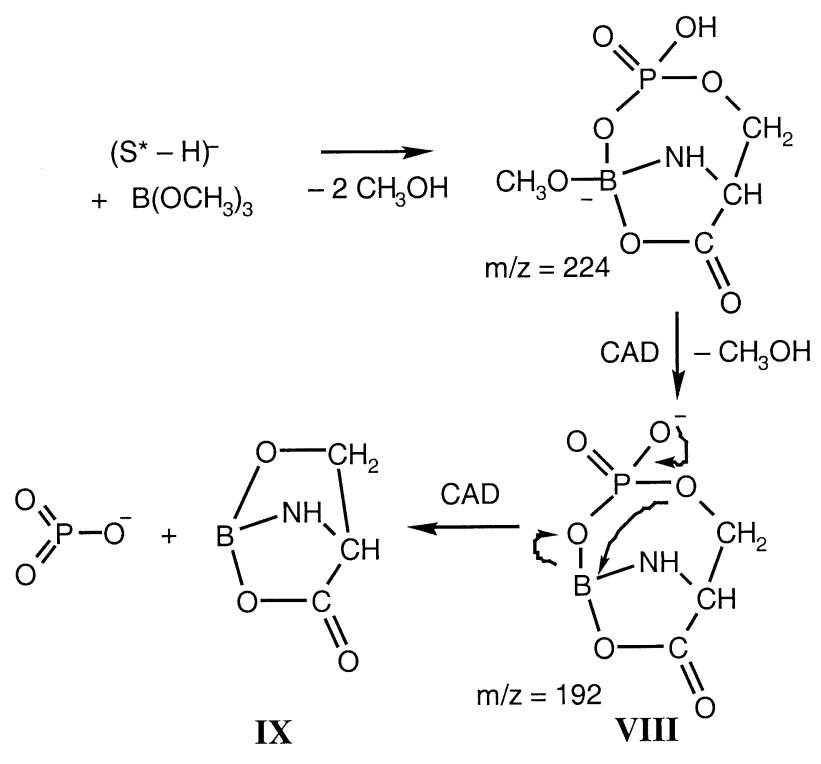

Scheme 4 
An interesting comparison can be made between the chemistry of deprotonated phosphoserine and the $\mathrm{H}_{2} \mathrm{PO}_{4}^{-}$(serine) cluster anion. The two differ in molecular formula by only one $\mathrm{H}_{2} \mathrm{O}$ molecule, but in one, the components are covalently linked whereas in the other, they are held together by hydrogen bonding. It should be noted that when subjected to $\mathrm{CAD}$, the $\mathrm{H}_{2} \mathrm{PO}_{4}^{-}$ (serine) cluster anion exclusively produces $\mathrm{H}_{2} \mathrm{PO}_{4}^{-}$. In the reaction of the $\mathrm{H}_{2} \mathrm{PO}_{4}^{-}$(serine) cluster anion with $\mathrm{TMB}$, the major product is addition with the loss of 2 $\mathrm{CH}_{3} \mathrm{OH}$ molecules to give an ion at $m / z=242$. When subjected to $\mathrm{CAD}$, this ion loses a third $\mathrm{CH}_{3} \mathrm{OH}$ to give an ion at $m / z=210$. Finally, CAD of the $m / z=210$ leads to the loss of $\mathrm{H}_{2} \mathrm{O}$ to produce an ion at $m / z=192$ which fragments in the same way as VIII (Scheme 4). Therefore it appears that the reaction of trimethyl borate with both phosphoserine and the $\mathrm{H}_{2} \mathrm{PO}_{4}^{-}$/serine complex eventually leads to the same product; however, it is doubtful that VIII is the shared intermediate. It is more likely that they share an intermediate where the phosphorous is no longer bound to the side-chain of the serine (i.e., part way on the path to IX). The similarity in the reactivity of these covalently and non-covalently bound anions again points to the ability of the boron to sequester the components of a cluster ion and allow for extensive reactivity involving the partners in the original non-covalent complex.

The complex of $\mathrm{H}_{2} \mathrm{PO}_{4}^{-}$with phosphoserine provides a system with an extensive number of possible nucleophilic sites for reaction with TMB. On its own, it fragments under CAD conditions to exclusively produce the phosphoserine $\mathrm{M}-\mathrm{H}$ anion indicating that $\mathrm{H}_{3} \mathrm{PO}_{4}$ is probably a weaker acid than phosphoserine. In the reaction with $\mathrm{TMB}$, the $\mathrm{H}_{2} \mathrm{PO}_{4}^{-}$(phosphoserine) complex mainly gives an ion at $\mathrm{m} / \mathrm{z}=322$ which corresponds to addition with loss of $2 \mathrm{CH}_{3} \mathrm{OH}$ molecules. When subjected to $\mathrm{CAD}$, the reaction product ion $(m / z=322)$ loses $\mathrm{CH}_{3} \mathrm{OH}$ to give an ion at $m / z=290$. $\mathrm{MS}^{4}$ and $\mathrm{MS}^{5}$ experiments indicate the sequential loss of $2 \mathrm{H}_{2} \mathrm{O}$ molecules to produce an ion at $m / z=254$. This ion then loses $\mathrm{CO}$ to give $m / z=226$ in an $\mathrm{MS}^{6}$ experiment indicating a breakdown of the phosphoserine backbone. Fragmentation of the $\mathrm{m} / \mathrm{z}=226$ ion mainly leads to the production of $\mathrm{PO}_{3}^{-}$and $\mathrm{HP}_{2} \mathrm{O}_{6}^{-}$ions. Given the complexity of this system, there are numerous reasonable structures for the species found in the reaction and fragmentation process, so it is difficult to identify preferred pathways. However, the data does clearly indicate that the boron is retained in the amino acid containing fragments.

The complex between phosphoserine and its $\mathrm{M}-\mathrm{H}$ anion provides the most complicated system in the study. When this complex is subjected to CAD, the dominant path is formation of the $\mathrm{M}-\mathrm{H}$ anion, but there is a small yield of an ion $(m / z=264)$ that corresponds to the loss of serine (Figure 6). This suggests that a nucleophilic substitution reaction is occurring on one of the phosphorous atoms leading to the displacement of the serine group. This path is almost

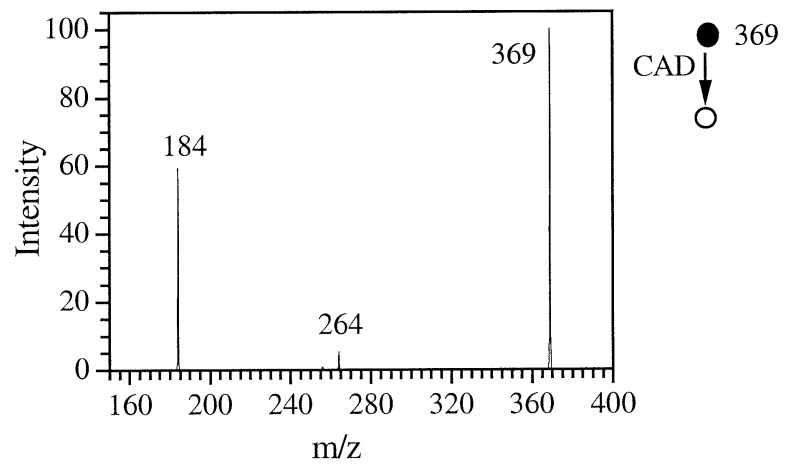

Figure 6. $\mathrm{CAD}$ of the complex of the phosphoserine $(\mathrm{M}-\mathrm{H})$ anion with phosphoserine $(\mathrm{m} / \mathrm{z}=369)$. Loss of phosphoserine appears at $m / z=184$ and loss of serine appears at $m / z=264$.

completely absent in the complex of $\mathrm{H}_{2} \mathrm{PO}_{4}^{-}$with phosphoserine so it is likely that a carboxyl group from one of the phosphoserines is acting as the nucleophile that attacks phosphorous. When this complex reacts with $\mathrm{TMB}$, addition with the loss of two $\mathrm{CH}_{3} \mathrm{OH}$ molecules is the pathway to give an ion at $m / z=409$. When subjected to $\mathrm{CAD}$, this ion first loses another $\mathrm{CH}_{3} \mathrm{OH}$ and then in an $\mathrm{MS}^{4}$ experiment, loses serine to give an ion at $m / z=272$. An $\mathrm{MS}^{5}$ experiment gives a loss of $\mathrm{H}_{2} \mathrm{O}$ to produce an ion at $m / z=254$ that appears to the same as the one formed in the fragmentation of the product from the reaction of the $\mathrm{H}_{2} \mathrm{PO}_{4}^{-}$(phosphoserine) complex with TMB. Again, the complexity of this system precludes presenting detailed reaction and fragmentation schemes, but it is clear that the boron is tightly binding both components of the complex.

\section{Reaction Rates}

Rate constants for reactions with TMB were determined for all of the systems described above and the results are compiled in Table 3. The simplest ion, $\mathrm{H}_{2} \mathrm{PO}_{4}^{-}$gives the highest rate constant and it appears that the reaction occurs at every collision. Reactivity in this system is clearly not controlled by base strength because $\mathrm{CH}_{3} \mathrm{CO}_{2}^{-}$is a much stronger base than $\mathrm{H}_{2} \mathrm{PO}_{4}^{-}$[17], but gives an immeasurably slow rate with TMB. Each of the complexes of $\mathrm{H}_{2} \mathrm{PO}_{4}^{-}$has a lower rate constant than the parent ion, but the differences are not dramatic and all of the efficiencies are over 0.04. For example, the complex with $\mathrm{H}_{3} \mathrm{PO}_{4}$ reacts about 4 times slower than the parent indicating that hydrogen bonding in the non-covalent complex modestly reduces the reactivity. With the $\mathrm{H}_{2} \mathrm{PO}_{4}^{-}$complexes of the carboxylic acid derivatives, there is a smooth reduction in reaction rate as the complexity (i.e., the number of possible coordination sites) increases and the phosphoserine complex provides the slowest reaction. The rate constants for the deprotonated amino acids (serine and phosphoserine) are also in Table 3, and it can be seen that they react faster than their complexes with phosphoric acid; however again, the differences are rather small amounting to less than a factor of 10 . The most dramatic effect on 
Table 3. Reaction rates with trimethyl borate ${ }^{\mathrm{a}}$

\begin{tabular}{lcrc}
\hline Anion & $\mathrm{k}_{\text {obs }}$ & $\mathrm{k}_{\mathrm{L}}{ }^{\mathrm{c}}$ & Efficiency \\
\hline \hline $\mathrm{H}_{2} \mathrm{PO}_{4}^{-}$ & $12.5 \pm 0.9$ & 10.3 & 1.17 \\
$\mathrm{H}_{2} \mathrm{PO}_{4}^{-}\left(\mathrm{H}_{3} \mathrm{PO}_{4}\right)$ & $2.7 \pm 0.1$ & 8.9 & 0.29 \\
$\mathrm{H}_{2} \mathrm{PO}_{4}^{-}\left(\mathrm{CH}_{3} \mathrm{CO}\right)$ & $1.6 \pm 0.1$ & 9.2 & 0.17 \\
$\mathrm{H}_{2} \mathrm{PO}_{4}^{-}(\mathrm{Ser})$ & $0.75 \pm 0.03$ & 8.8 & 0.082 \\
$\mathrm{H}_{2} \mathrm{PO}_{4}^{-}\left(\mathrm{Ser}^{*}\right)^{\mathrm{b}}$ & $0.41 \pm 0.01$ & 8.4 & 0.047 \\
$(\mathrm{Ser}-\mathrm{H})^{-}$ & $0.95 \pm 0.02$ & 10.1 & 0.090 \\
$\left(\mathrm{Ser}^{*}-\mathrm{H}\right)^{-}$ & $2.9 \pm 0.2$ & 9.0 & 0.31 \\
$\left(\mathrm{Ser}^{*}-\mathrm{H}\right)^{-}\left(\mathrm{Ser}^{*}\right)$ & $0.025 \pm 0.001$ & 8.1 & 0.003 \\
\hline
\end{tabular}

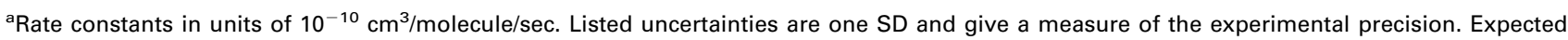
absolute uncertainties are \pm 25

ber* represents O-phosphoserine.

'Langevin rate constant-TMB requires no dipole correction.

the TMB rate constants is seen when comparing the reaction of the phosphoserine $(\mathrm{M}-\mathrm{H})$ anion with that of its complex with phosphoserine. Here, a rate reduction of over 100-fold is seen indicating that hydrogen bonding within the complex is severely reducing the nucleophilicity of the anionic site.

\section{Discussion}

The most remarkable aspect of this study is that in all of the reactions of the non-covalent complexes with TMB, neither component of the complex is lost in the initial reaction. The addition to the boron center is obviously exothermic, but this energy is never used to expel the solvating group. Instead, one or two $\mathrm{CH}_{3} \mathrm{OH}$ molecules are lost in every case. In other words, the initially weak, non-covalent linkage is retained at the expense of covalent bonds to boron. This is an overstatement because the components of the hydrogen bonded complex eventually become covalently bound to the boron, but it is still striking that the boron so efficiently captures both partners from the non-covalent complex. Two factors are important for understanding this result. First, boron has a flexible valency (tri- or tetracoordinate) that can facilitate addition/elimination processes for swapping ligands. Second, in competition with a proton, there is a thermodynamic advantage for boron to bond to the weaker base. For example, the computational work above showed that it was more favorable to eliminate $\mathrm{CH}_{3} \mathrm{OH}$ rather $\mathrm{CH}_{3} \mathrm{CO}_{2} \mathrm{H}$ from the tetracoordinate borate (i.e., the weaker base, $\mathrm{CH}_{3} \mathrm{CO}_{2}^{-}$, stays with boron and the stronger base, $\mathrm{CH}_{3} \mathrm{O}^{-}$, accepts the proton). In other words, there tend to be greater variations in proton affinities than in boron affinities, so it is the proton acceptor that dominates the thermochemistry (i.e., the stronger base gets the proton). This is true as long as the fragmentation product can adopt a tetracoordinate geometry for the boron center (see above). Given that all of the species used to make the complexes in this study are weaker bases than $\mathrm{CH}_{3} \mathrm{O}^{-}$, it is not surprising that they would prefer to be associated with the boron. Nonetheless, it is remarkable that the system is able to undergo all the rearrangements necessary to reach the thermodynamically preferred products with- out occasionally expelling the weakly bound partner of the reactant ion complex. This is highlighted by the fact that there are so many literature examples of solvated ions reacting in such a way that one of the partners is lost (termed solvent or ligand switching reactions) $[19,20]$.

Overall, the reactions show a rather consistent pattern. The exothermic addition of the anion to the tricoordinate boron leads to the expulsion of one or two $\mathrm{CH}_{3} \mathrm{OH}$ molecules, probably depending on the exothermicity of the addition process and the availability of acidic protons in the reactant (see below). If not lost in the initial reaction, the second $\mathrm{CH}_{3} \mathrm{OH}$ molecule is lost during the first CAD process. At this point, there is some variation in the reactivity. If there are still acidic hydrogens available to protonate the leaving group, a third $\mathrm{CH}_{3} \mathrm{OH}$ molecule is lost. This is not the case for the reaction of $\mathrm{H}_{2} \mathrm{PO}_{4}^{-}$with TMB and after the loss of two $\mathrm{CH}_{3} \mathrm{OH}$ molecules, the heavy atom framework breaks down during $\mathrm{CAD}$ to give $\mathrm{PO}_{3}^{-}$as the product (eq 1). The only exception to this generalization is the reaction of $\mathrm{H}_{2} \mathrm{PO}_{4}^{-} \quad\left(\mathrm{CH}_{3} \mathrm{CO}_{2} \mathrm{H}\right)$ with TMB where $\mathrm{CH}_{3} \mathrm{CO}_{2} \mathrm{H}$ is lost instead of the third $\mathrm{CH}_{3} \mathrm{OH}$ during $\mathrm{CAD}$ despite the presence of an acidic hydrogen (Scheme 3); however, as noted above, the thermochemistry favors loss of $\mathrm{CH}_{3} \mathrm{CO}_{2} \mathrm{H}$ rather than $\mathrm{CH}_{3} \mathrm{OH}$ in this case. After all three $\mathrm{CH}_{3} \mathrm{OH}$ molecules have been lost, these systems fragment in a number of ways often leading to phosphorous oxide anions (i.e., $\mathrm{PO}_{3}^{-}$and $\mathrm{HP}_{2} \mathrm{O}_{6}^{-}$) and a breakdown of the heavy atom framework around the boron. The prevalence of these products is probably a result of their relatively high stability.

The reaction rates clearly indicate that the basicity of the reactant is not the key to the efficiency of the reaction. However, the data can be explained by assuming that after the addition, there must be a relatively acidic hydrogen that can act as proton donor for the departing methoxide. Orientation is probably important and it appears that $\mathrm{H}_{2} \mathrm{PO}_{4}^{-}$provides nearly the ideal situation. After the exothermic addition of the oxy anion to boron, there are two hydroxyl groups on phosphorous that are close to the boron's methoxy groups and are suitable proton donors. A sample transition state for the expulsion is shown in Figure 7 and it 


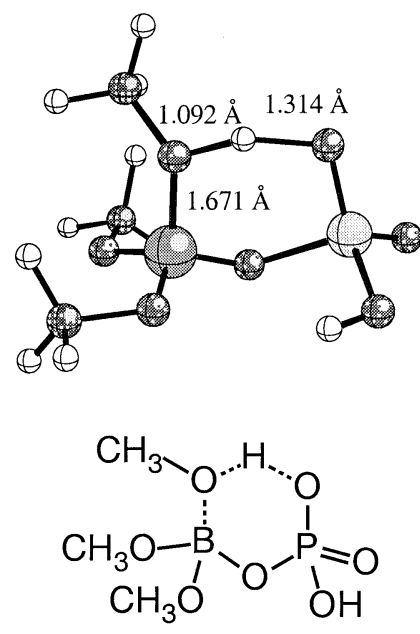

Figure 7. Computed structure (PM3) of the transition state involved in the expulsion of $\mathrm{CH}_{3} \mathrm{OH}$ during the reaction of $\mathrm{H}_{2} \mathrm{PO}_{4}^{-}$ with TMB.

is clear that the distances and bond angles are appropriate for a nearly strain-free process. As a result, this reaction can proceed at the collision-controlled limit. The fact that the $\mathrm{M}-\mathrm{H}$ anion of serine reacts with TMB whereas acetate does not, is also easily rationalized by the need for an acidic hydrogen in the reactant. Although acetate is a stronger base and should give a more exothermic addition to boron, there are no easily available hydrogens for a departing methoxide, so the system expels acetate to give a non-productive collision process. Although it is likely that the methyl hydrogens of the acetate ligand are sufficiently acidic to protonate a departing methoxide, the process would not be as kinetically facile as the deprotonation of a hydroxyl group. In serine, the amine or the alcohol functional groups can provide the needed proton. From our related studies of the reactions of boron and aluminum reagents with simple amino acids, it is clear that the reaction pathways can be more complicated than this simple model suggests (i.e., addition can occur at the N-terminal amine to give a salt-bridge structure), but the need for an acidic hydrogen near the addition site is still a requirement [12]. Overall, it appears that the structural motif in Scheme $\mathbf{5}$ is a key component for efficient reactions with TMB.

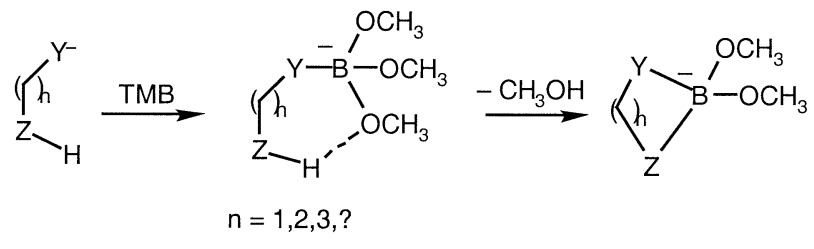

Scheme 5

\section{Summary}

Trimethyl borate reacts rapidly with phosphate containing species to give addition products with the loss of one or more $\mathrm{CH}_{3} \mathrm{OH}$ molecules. When the reactant is a hydrogen-bonded complex, it appears that the boron forms covalent bonds to both partners. Despite the relatively weak interaction in these hydrogen-bonded complexes, neither partner is lost in any of the reactions or in the initial round of CAD. This is partly a result of the boron generally preferring to expel the most basic ligand, which is methoxide in all of the examples in this study. Repeated CAD of the reaction products generally leads to the formation of novel borophosphates as well as simple phosphorous containing anions such as $\mathrm{H}_{2} \mathrm{PO}_{4}^{-}, \mathrm{PO}_{3}^{-}$, and $\mathrm{HP}_{2} \mathrm{O}_{6}^{-}$. The reaction rates do not correlate with the basicity of the reactant ion and it appears that the availability of a relatively acidic hydrogen near the boron addition site is the key to a rapid reaction. Therefore, despite the low basicity of phosphates, they react quickly with TMB because of the favorable orientation of the oxy-anion and hydroxyl groups on the phosphorous.

\section{Acknowledgments}

S.G. thanks the University of Melbourne for a Wilsmore Fellowship and San Francisco State University for sabbatical support. S.G also acknowledges generous financial support from the National Center for Research Resources (Research Infrastructure in Minority Institutions P20 RR11805) of the National Institutes of Health. R.A.J.O. thanks the Australian Research Council for financial support (grant \# A29930202) and the University of Melbourne for funds to purchase the LCQ. Finally, the authors wish to thank the referees for many helpful and insightful comments.

\section{References}

1. Hayes, R. N.; Sheldon, J. C.; Bowie, J. H. A Comparison of the Reactivity of Alkoxide and Alkoxide-Alkanol Negative Ions with Alkyl- and Alkoxyboranes in the Gas Phase. An Ion Cyclotron Resonance and $\mathrm{Ab}$ Initio Study. Organometallics 1986, 5, 162.

2. van der Wel, H.; Nibbering, N. M. M.; Sheldon, J. C.; Hayes, R. N.; Bowie, J. H. Nucleophilic Substitution in the Gas Phase. The Reactions of Alkoxide-Alkanol Negative Ions with Boron, Carbon, Silicon, and Titanium Alkoxides. An Ion Cyclotron Resonance and Ab Initio Study. J. Am. Chem. Soc. 1987, 109, 5823.

3. Suming, H.; Yaozu, C.; Longfei, J.; Shuman, X. Stereochemical Effects in Mass Spectrometry. 2. Chemical-Ionization Mass Spectra of Some Cyclic Glycols and Mono- and Disaccharides Using Trimethyl Borate as Reagent Gas. Org. Mass Spectrom. 1985, 20, 719.

4. Kiplinger, J. P.; Crowder, C. A.; Sorensen, D. N.; Bartmess, J. E. Gas-Phase Ion-Molecule Chemistry of Borate and Boronate Esters. J. Am. Soc. Mass Spectrom. 1994, 5, 169.

5. Morris, R. A.; Knighton, W. B.; Viggiano, A. A.; Hoffman, B. C.; Schaefer, H. F., III. The Gas-Phase Acidity of $\mathrm{H}_{3} \mathrm{PO}_{4}$. J. Chem. Phys. 1997, 106, 3545.

6. Reid, G. E.; O'Hair, R. A. J.; Styles, M. L.; McFadyen, W. D.; Simpson, R. J. Gas Phase Ion-Molecule Reactions in a Modified Ion Trap: H/D Exchange of Non-Covalent Complexes and Coordinatively Unsaturated Platinum Complexes. Rapid Commun. Mass Spectrom. 1998, 12, 1701.

7. Gronert, S.; Pratt, L. M.; Mogali, S. Substituent Effects in Gas Phase Substitutions and Eliminations: Beta-Halo Substituents. 
Solvation Reverses $\mathrm{S}_{\mathrm{N}} 2$ Substituent Effects. J. Am. Chem. Soc. 2001, 123, 3081.

8. Gronert, S. Estimation of Effective Ion Temperatures in a Quadrupole Ion Trap. J. Am. Soc. Mass Spectrom. 1998, 9, 845.

9. Gaussian 94 Revision B.3: Frisch, M. J.; Trucks, G. W.; Schlegel, H. B. W.; Gill, P. M.; Johnson, B. G.; Robb, M. A.; Cheeseman, J. R.; Keith, T.; Petersson, G. A.; Montgomery, J. A.; Raghavachari, K.; Al-Laham, M. A.; Zakrzewski, V. G.; Ortiz, J. V.; Foresman, J. B.; Peng, C. Y.; Ayala, P. Y.; Chen, W.; Wong, M. W.; Andres, J. L.; Replogle, E. S.; Gomperts, R.; Martin, R. L.; Fox, D. J.; Binkley, J. S.; Defrees, D. J.; Baker, J.; Stewart, J. P.; Head-Gordon, M.; Gonzalez, C.; Pople, J. A.; Gaussian, Inc.: Pittsburgh PA, 1995.

10. Gaussian 98 Revision A.7: Frisch, M. J.; Trucks, G. W.; Schlegel, H. B.; Scuseria, G. E.; Robb, M. A.; Cheeseman, J. R.; Zakrzewski, V. G.; Montgomery, J. A.; Stratmann, R. E.; Burant, J. C.; Dapprich, S.; Millam, J. M.; Daniels, A. D.; Kudin, K. N.; Strain, M. C.; Farkas, O. J.; Tomasi Barone, V.; Cossi, M.; Cammi, R.; Mennucci, B.; Pomelli, C.; Adamo, C.; Clifford, S.; Ochterski, J.; Morokuma Malick, D. K.; Rabuck, A. D.; Raghavachari, K.; Foresman, J. B.; Cioslowski, J.; Ortiz, J. V.; Stefanov, B. B.; Liu, G. A.; Liashenko Piskorz, P.; Komaromi, I.; Gomperts, R.; Martin, R. L.; Fox, D. J.; Keith, T.; Al-Laham, M. A.; Peng, C. Y.; Nanayakkara, A.; Gonzalez, C.; Challacombe, M.; Gill, P. M. W.; Johnson, B. G.; Chen, W.; Wong, M. W.; Andres, J. L.; Head-Gordon, M.; Replogle, E. S.; Pople, J. A.; Gaussian, Inc.: Pittsburgh, PA, 1998.

11. Pople, J. A.; Scott, A. P.; Wong, M. W.; Radom, L. Scaling Factors for Obtaining Fundamental Vibrational Frequencies and Zero-Point Energies from HF/6-31G* and MP2/631G* Harmonic Frequencies. Isr. J. Chem. 1993, 33, 345.

12. Gronert, S.; Huang, R. A Strong Preference for a Salt-Bridge Structure in the Gas Phase: Reactions of Deprotonated Amino Acids with Borane. J. Am. Chem. Soc. 2001, 123, 8606.

13. Kniep, R.; Boy, I.; Engelhardt, H. $\mathrm{RbFe}\left[\mathrm{BP}_{2} \mathrm{P}_{8}(\mathrm{OH})\right]$ : A New Borophosphate Containing Open-Branched Tetrahedral ViereEinfach Chains. Z. Anorg. Allg. Chem. 1999, 625, 1512.

14. Cullis, P. M.; Schilling, M. B. The Reactivity of Adenosine 5'-O-(S-Methyl-1-Thiotriphosphate): A Facile Way of Generating Cyclo-Diphosphate Dianion. J. Chem. Soc., Chem. Commun. 1989, 106.

15. Morris, R. A.; Viggiano, A. A. Chemistry of $\mathrm{PO}^{-}, \mathrm{PO}_{2}^{-}$, and $\mathrm{PO}_{3}^{-}$in the Gas Phase. J. Chem. Phys. 1998, 109, 4126.

16. MacSpartan Plus: Deppmeier, B. J.; Driessen, A. J.; Hehre, W. J.; Johnson, J. A.; Kluzinger, P. E.; Lou, L.; Yu, J.; Wavefunction. Inc.: Irvine, CA1996.

17. Bartmess, J. E. In NIST Standard Reference Database Number 69; Mallard, W. G., Linstrom, P. J., Eds.; National Institute of Standards and Technology (http://webbook.nist.gov): Gaithersburg MD, 2000.

18. O'Hair, R. A. J.; Bowie, J. H.; Gronert, S. Gas Phase Acidities of the Alpha Amino Acids. Int. J. Mass Spectrom. Ion Processes 1992, 117, 23.

19. Takashima, K.; Riveros, J. M. Gas-Phase Solvated Negative Ions. Mass Spectrom. Rev. 1998, 17, 409.

20. Filippi, A.; Speranza, M. Gas-Phase Reactivity of Diastereomeric Acetate Ion/Tributylborate Complexes. Int. J. Mass Spectrom. 2000, 199, 211. 